\title{
LA PENA CON RESTRICCIÓN DE LA LIBERTAD EN EL ACUERDO DE PAZ: VISIÓN GEOPOLÍTICA DEL TRATADO FIRMADO ENTRE EL GOBIERNO DE COLOMBIA $\Upsilon$ LA FUERZA ARMADA DE REVOLUCIÓN DE COLOMBIA
}

A PENA COM RETRIÇÃO À LIBERDADE NO ACORDO DE PAZ: VISÃO GEOPOLÍTICA DO TRATADO FIRMADO ENTRE O COVERNO DA COLÔMBIA E AS FORÇAS ARMADAS REVOLUCIONÁRIAS DA COLÔMBIA

THE PENALTY WITH RESTRICTION OF FREEDOM IN THE PEACE AGREEMENT: GEOPOLITICAL VISION OF THE TREATY SIGNED BETWEEN THE GOVERNMENT OF COLOMBIA AND THE REVOLUTIONARY ARMED FORCES OF COLOMBIA

\section{Juan Marcelino González Garcete ${ }^{1}$}

Licença CC BY: Artigo distribuído sob os termos Creative Commons, permite uso e distribuição irrestrita em qualquer meio desde que o autor credite a fonte original.

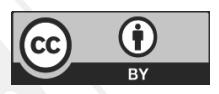

\begin{abstract}
Resumen: La fuerza armada de revolución colombiana es un grupo al margen de la ley en Colombia que ha cometido delitos que violan los derechos humanos. Actualmente este grupo ilegal se encuentra en diálogos con el gobierno colombiano con el fin de llegar a un acuerdo de paz motivo por el cual en este trabajo tenemos que remitirnos a los pactos y convenciones internacionales para verificar si lo que plantea el gobierno en el comunicado 060 del 2015 se acoge a las normas internacionales.
\end{abstract}

Palabras clave: Paz, acuerdo, pacto, convenciones, derechos humanos.

Resumo: As forças armadas revolucionárias da Colômbia são um grupo de indivíduos à margem da lei que cometeram crimes contra direitos humanos. Atualmente, este grupo está em discussões com o governo colombiano para chegar a um acordo de paz. Por esta razão, neste trabalho usamos como referência acordos e convenções internacionais para verificar se o que o governo pretende com o comunicado oficial 060 de 2015 está em linha com a legislação internacional.

1 Postdoctorado en Derecho por la IMED. Doctor en Ciencias Jurídicas por la FDCS de la Universidad Nacional de Asunción. Doctor en Ciencias Políticas por la FDCS de la Universidad Nacional de Asunción. Magíster en Derecho Penal por la Universidad Columbia. Magíster en Derecho Procesal Penal por la Universidad Columbia. Magíster en Ciencias Forenses. Profesor de la Escuela Judicial del Paraguay. Profesor de Doctorado de la Facultad de Derecho y Ciencias Sociales de la Universidad Nacional de Asunción, de la Universidad Tecnológica Intercontinental, de la Universidad del Pacífico. Conferencista Internacional. Tratadista. 
Palavras-chave: Paz, acordo, pacto, convenção, direitos humanos.

Abstract: The revolutionary armed forces of Colombia are a group outside the law that has committed human rights violations. Today, this illegal group is in talks with the Colombian government in order to reach a peace agreement. In this work, we use the international conventions as a reference, to determine whether the government's goal, with its official statement 060 of 2015 , is in line with the international legislation.

Keywords: Peace agreement, covenant, convention, human rights.

\section{INTRODUCCIÓN}

Este artículo es obra de la investigación realizada en mi carácter de investigador invitado por la Universidad Católica de Colombia. Uno de los temas que ha tomado importancia a nivel mundial en la actualidad, es la lucha por encontrar la justicia y la igualdad como elementos esenciales de la paz, teniendo en cuenta que Colombia sostiene en La Habana, Cuba, un diálogo con la Fuerza Armada de Revolución Colombiana (FARC) para llegar a un acuerdo de paz, se vio la importancia en este trabajo de buscar y analizar aquellas normas internacionales que regulan o protegen los derechos humanos de las personas $y$ de esta forma estudiar si estas permiten un acuerdo de paz $y$, de permitirlo, determinar si el acuerdo que plantea el gobierno colombiano con la guerrilla denominada Fuerza Armada de Revolución Colombiana (FARC) se acojo o no a las normas internacionales sobre derechos humanos.

\section{LA PENA PRIVATIVA DE LA LIBERTAD EN EL ACUERDO DE PAZ ENTRE COLOMBIA Y LAS FUERZAS ARMADAS REVOLUCIONARIAS DE COLOMBIA (FARC)}

El 23 de septiembre del 2015 el Gobierno Colombiano y las FARC-EP sacan un comunicado donde reafirman su compromiso en la búsqueda de la paz y para ello plantean una jurisdicción especial para la paz que se encargará de juzgar los delitos cometidos contra los derechos humanos por este grupo ilegal o, quienes hayan intervenido en el conflicto, en esta jurisdicción se plantea crear tribunales especiales conformados en su mayoría por jueces colombianos y solo una minoría de jueces extranjeros.

A raíz de ese comunicado se comenzó a especular sobre si los integrantes 
de este grupo ilegal iban a ser juzgados por la ley ordinaria o no, respecto a la inquietud que surge hay que tener clara una cosa y es que si estamos hablando de un acuerdo entre un Estado y un grupo ilegal con el fin de buscar la paz, no podemos pretender someter a los integrantes de ese grupo a un juzgamiento con una justicia ordinaria, pues precisamente esto es lo que no ha permitido que entreguen sus armas, más aun si no hay motivación para su desmovilización.

Si se plantea un acuerdo donde la otra parte se somete al poder del otro, en este caso al poder del Estado, no tendría sentido dicho acuerdo para los integrantes de la guerrilla de la FARC, por eso han acordado unos puntos donde ambos llegan a un equilibrio para llegar a un acuerdo de paz, entre estos puntos los más polémicos son los que se plantean respecto a las condenas, está están plasmadas en los puntos sexto y séptimo, los cuales dicen:

6. La Jurisdicción Especial para la Paz contempla dos tipos de procedimientos: uno para quienes reconocen verdad y responsabilidad, y otro para quienes no lo hacen o lo hacen tardíamente. A los primeros se les impondrá una sentencia, fundada en las conductas reconocidas después de haber sido contrastadas las investigaciones de la Fiscalía General de la Nación, las sanciones impuestas por otros órganos del Estado, las sentencias judiciales existentes, así como la información que provean las organizaciones de víctimas y de derechos humanos. Los segundos enfrentarán un juicio contradictorio ante el Tribunal.

7. Las sanciones que imponga el Tribunal tendrán como finalidad esencial satisfacer los derechos de las víctimas y consolidar la paz y deberán tener la mayor función restaurativa y reparadora del daño causado. Para todos aquellos que reconozcan responsabilidades por los delitos competencia del Sistema, la sanción tendrá un componente de restricción de libertades y derechos que garantice el cumplimiento de las funciones reparadoras y restauradoras de las mismas mediante la realización de trabajos, obras y actividades y en general la satisfacción de los derechos de las víctimas. Las sanciones para quienes reconozcan delitos muy graves tendrán un mínimo de duración de cumplimiento de 5 años y un máximo de 8 de restricción efectiva de la libertad, en condiciones especiales. Las personas que hagan dicho reconocimiento de manera tardía ante el Tribunal serán sancionadas con pena de prisión de 5 a 8 años, en condiciones ordinarias. Para tener derecho a la pena alternativa, se requerirá que el beneficiario se comprometa a contribuir con su resocialización a través del trabajo, capacitación o estudio durante el tiempo que permanezca privado de la libertad. 
Las personas que se nieguen a reconocer su responsabilidad por tales delitos y resulten culpables serán condenadas a pena de prisión hasta de 20 años, en condiciones ordinarias ${ }^{2}$.

Del comunicado que se dio a conocer vamos a ver si lo que plantea el gobierno colombiano y la FARC se ajusta o no a los acuerdos internacionales más exactamente en los puntos que hemos relacionados, estos han sido los más polémicos ya que sus contradictores manifiestan que este no se cumple con las convenciones internacionales ya que este grupo ilegal de la FARC ha cometido delitos contra la población civil que van en contra de estas convenciones.

\section{HISTORIA DE LAS FUERZAS ARMADAS REVOLUCIONARIAS DE COLOMBIA (FARC)}

Las Fuerzas Armadas Revolucionarias de Colombia (FARC) se crea en el año de 1964 tras una ofensiva del gobierno colombiano contra la llamada República de Marquetalia que era un pequeño territorio del corregimiento de Gaitania, municipio de Planadas en el departamento del Tolima en Colombia. Este territorio se encontraba sin control por parte del estado y allí habitaba una comunidad de campesinos comunistas alzados en armas.

Los fundadores de este grupo fueron Manuel Marulanda (alias Tirofijo), y Jacobo Arenas, líderes e ideólogos de la guerrilla quienes también hacían parte de la antes República marquetalia, este nuevo grupo se crea con la ideología de luchar contra el imperialismo y la oligarquía.

Su creación se da con el fin de acabar con las desigualdades sociales, políticas y económicas de nuestro país, su defensa siempre ha sido a través de las armas, sin embargo, con el pasar del tiempo sus ideologías se fueron desviando cuando comenzaron a cometer acciones en contra de la población civil, pues pensaron que este método podía ser una forma de presión para que el Estado se rindiera, cosa que nunca paso pues un Estado debe mantener su soberanía.

En esta guerra este grupo ilegal cometió muchas delitos y muertes a personas inocentes que nada tuvieron que ver con el conflicto armado, su método de financiación era a través de los secuestros extorsivos y la destrucción de la infraestructura de las ciudades.

2 Comunicado 060 del 2015 del gobierno colombiano. 
Uno de los delitos más notorios fue el secuestro de los diputados del valle y años más tarde el cruel asesinato atribuido y reconocido por este mismo grupo, pues al reconocer los hechos absurdamente se justificaron diciendo que lo hicieron por los constantes operativos que el ejército sostenía sobre ellos y ni decir del secuestro de Ingrid Betancourt y los contratista estadunidenses entre otros, pues son violaciones tan notorias en contra de los derechos humanos que no se podían ocultar más aun cuando el mundo entero supo de estos hechos, afortunadamente las víctimas fueron rescatadas en un operativo que los expertos calificaron como un operación perfecta, pues no hubo que disparar una sola bala, tal vez fue ese el día que después de años de guerra el gobierno colombiano ponía en burla a la Farc ante el mundo entero y fue ahí donde empezaron una serie de aciertos del gobierno.

Como lo dije anteriormente la Farc rechazo algunos actos y otros que eran imposibles ocultarlos termino reconociéndolos y dentro de estos, la mayoría fueron violatorios a los derechos humanos.

\subsection{ACTUALIDAD DE LAS FUERZAS ARMADAS REVOLUCIONARIAS}

En la actualidad este grupo se encuentra en diálogos con el gobierno para la búsqueda de la paz, como lo dije anteriormente el gobierno saco el comunicado número 60 del 2015 que habla sobre la creación de una Jurisdicción Especial para la Paz, en este comunicado en los puntos seis y siete se tratan los temas respecto de las condenas o penas y como se van a materializar.

Este tema ha sido uno de los más polémicos del diálogo que sostiene el gobierno colombiano con las FARC en la Habana, pero independiente de sus polémicas, de personas a favor y contradictores de dicho acuerdo es importante saber si este se acoge o no a la Constitución y más aún a los Derecho Humanos y la Corte Penal Internacional, para ellos hay que revisar algunas convenciones y hacer un estudio de convencionalidad para saber si este se adapta a la Constitución $y$, a la vez, a las convenciones de derechos humanos, lo que si debemos tener en cuenta es que estamos ante un posible acuerdo histórico el cual requiere de sacrificios para encontrar un futuro mejor para las nuevas generaciones.

Por todo lo anterior expuesto vamos a entrar en materia y para ello vamos a ver si los actos cometidos por este grupo ilegal que van en contra de los derechos 
humanos pueden ser en alguna manera negociables o no por las partes, primero que todo vamos aclarar algunos conceptos como la definición jurídica de delito y posteriormente que es la pena y su objetivo, ya que esta tiene ciertos elementos y finalidades que busca la recuperación o la resocialización del delincuente para volver a integrarse a la vida social, si no se cumple con los elementos que conforma la pena estaríamos hablando de una forma de venganza individual hacia el delincuente y no de un bien común que permita una convivencia en armonía.

\section{EL DELITO}

La palabra delito viene del latín "delinquere" que significa apartarse del buen camino, alejarse de las reglas señaladas por la ley. Es el actuar de un individuo cuyo acto es reprochado por la sociedad y afecta el bienestar de terceros, por tal motivo este comportamiento tiene una intimidación de prohibición por parte del Estado, es decir, que se le dice a la persona que si comente un acto que este tipificado como delito tendrá como castigo una sanción, pero a la vez le dice al que decide cometer el delito que por el hecho de cometer esa conducta a sabiendas de sus consecuencias tendrá un castigo del cual se le restringirá algunos derechos entre ellos podría llegar a ser la libertad.

La Corte penal Internacional tiene dentro de su competencia ciertos delitos internacionales que afectan los derechos inherentes de las personas, es decir aquellos derechos que no pueden ser violados pues de hacerlo se estaría afectando la vida digna de la persona y más aún podría poner en riesgo la misma vida.

La Corte Penal Internacional divide los delitos internacionales en cuatro categorías y dentro de estos deberán encajar los hechos o actos cometidos para que de esta manera se considere como delitos internacionales, de no ser así tendríamos que descartarlo de la competencia la Corte Penal internacional, estas categorías están divididas de la siguiente forma:

\subsection{GENOCIDIO}

Es la acción perpetrada con el fin de destruir total o parcialmente a un grupo que puede ser nacional, étnico, religioso entre otros. Este es uno de los delitos considerados más graves pues busca eliminar o exterminar una cultura o un grupo 
de personas consideradas inferiores. Unos de los casos más claros de genocidio es el holocausto nazi donde hubo cerca de seis millones de personas muertas.

Por lo general este tipo de delitos lo cometen los Gobiernos de turno, pero también pueden ser cometidos por grupos ilegales, la Corte Internacional ha considerado genocidio los siguientes actos:

- Matanzas de miembros del grupo.

- Lesión grave a la integridad física o mental de los miembros del grupo.

- Sometimiento intencional del grupo a condiciones de existencia que hayan de acarrear su destrucción física, total o parcial.

- Medidas destinadas a impedir nacimientos en el seno del grupo.

- Traslado por la fuerza de niños del grupo a otro grupo. ${ }^{3}$

\subsection{CRIMEN DE LESA HUMANIDAD}

Son ataques cometidos a una población civil, son ataques inhumanos como la tortura, esclavitud entre otro, la Corte Penal Internacional pone dos requisitos para considerar que un hecho es un delito de lesa humanidad y dichos requisitos son los siguientes:

Primero: La comisión como parte de un ataque generalizado o sistemático contra una población civil, es decir que como resultado de dicho ataque se obtiene una gran cantidad de víctimas civiles, entiéndase por civiles aquellas personas que no son combatientes ni hacen parte del conflicto.

Segundo: con conocimiento de dicho ataque, es decir que las personas que van a cometer el acto saben y son conscientes de lo que van a hacer".

Estos dos elementos son esenciales para que un hecho sea considerado delito de lesa humanidad, este puede ser cometido por un grupo ilegal como 3 Corte Penal Internacional.

4 Corte Penal Internacional. 
también por el propio Estado; lo que buscan las normas internacionales es apartar del conflicto armado a los civiles que no hacen parte de la guerra, en otras palabras, les dice a las partes en conflicto que si van a pelear lo hagan entre ellos sin vincular a personas ajenas a su conflicto.

\subsection{CRÍMENES DE GUERRA}

Son los que van en contra del derecho internacional humanitario, en caso de los conflictos internos los que van en contra del artículo 3 del Convenio de Ginebra de 1949 que dice:

Artículo 3: En caso de conflicto armado que no sea de índole Internacional y que surja en el territorio de una de las Altas Partes Contratantes cada una de las Partes en conflicto tendrá la obligación de aplicar, como mínimo, las siguientes disposiciones:

1) Las personas que no participen directamente en las hostilidades, incluidos los miembros de las fuerzas armadas que hayan depuesto las armas y las personas puestas fuera de combate por enfermedad, herida, detención o por cualquier otra causa, serán, en todas las circunstancias, tratadas con humanidad, sin distinción alguna de índole desfavorable basada en la raza, el color, la religión o la creencia, el sexo, el nacimiento o la fortuna o cualquier otro criterio análogo. A este respecto, se prohíben, en cualquier tiempo y lugar, por lo que atañe a las personas arriba mencionadas:

a) Los atentados contra la vida y la integridad corporal, especialmente el homicidio en todas sus formas, las mutilaciones, los tratos crueles, la tortura y los suplicios;

b) la toma de rehenes;

c) los atentados contra la dignidad personal, especialmente los tratos humillantes y degradantes;

d) las condenas dictadas y las ejecuciones sin previo juicio ante un tribunal legítimamente constituido, con garantías judiciales reconocidas como indispensables por los pueblos civilizados.

2) Los heridos y los enfermos serán recogidos y asistidos. Un organismo humanitario imparcial, tal como el Comité Internacional de la Cruz Roja, podrá ofrecer sus servicios a las Partes en conflicto. Además, las Partes en conflicto harán lo posible por poner en vigor, mediante acuerdos especiales, la totalidad o parte de las otras disposiciones del presente Convenio. La aplicación de las anteriores disposiciones no surtirá efectos sobre el estatuto jurídico de las Partes en conflicto. ${ }^{5}$

5 Convenio de Ginebra de1949. 


\subsection{CRÍMENES DE AGRESIÓN}

Son aquellos crímenes contra la paz, es la fuerza armada que utiliza un Estado contra otro sin justificación, respecto a este tipo de crímenes no ha habido sentencias ya que solo en enero del 2017 cuando al Estado le den la jurisdicción a la Corte se conocerán estos tipos de delitos.

\section{LA PENA}

La pena es la restricción de ciertos derechos de una persona como consecuencia de una sanción por un hecho o acto cometido que va en contra de la ley.

Muchas personas ven la pena como una venganza, pero la verdad es que la pena es una retribución de un hecho cometido y su función es resocializar al delincuente para que este no vuelva a delinquir.

Uno de los ejemplos claros de que la pena no es una venganza, lo podemos ver relacionado en la constitución española que en su artículo 25 numeral dos dice:

Las penas privativas de libertad y las medidas de seguridad estarán orientadas hacia la reeducación y reinserción social y no podrán consistir en trabajos forzados... ${ }^{6}$, pues si fuese una venganza y si infringiera dolor, se estaría en contra del derecho internacional humanitario, afectando la dignidad del condenado.

Una teoría clara de la resocialización es la teoría de la enmienda o correccionalista que busca que el delincuente no reincida en sus actos y procura la reeducación del delincuente.

\subsection{TIPOS DE PENAS}

Cuando hablamos de penas o condenas no podemos pensar solo en cárcel, pues la pena se toma como una sanción para el que infringe la ley, pero no solo la puede infligir de tipo penal, pues puede haber sanciones administrativas, contravenciones, fiscales, morales, entre otras dependiendo la acción realizada.

A continuación, vamos a ver los tipos de penas que existen en las diferentes condenas.

6 constitución española de 1978. 
Son aquellas condenas que afecta la honra de la persona, la desacreditación de la misma, en algunos casos son los llamados delitos militares como por ejemplo la degradación, en otros casos o grupo étnico pueden ser condena a azotes.

\subsection{PENA PRIVATIVA DE DERECHOS}

Las penas privativas de derechos son aquellos en los cuales se restringen algunos derechos del condenado como por ejemplo el derecho a votos, cuando el padre no cumple con sus deberes como padre y le quitan la patria potestad de su hijo o cuando a un profesional es sancionado y le restringe temporal, parcial o totalmente el ejercicio de su función.

\subsection{PENAS PRIVATIVAS DE LIBERTAD}

Son aquellas condenas en la cual se le restringe la libertad al condenado por un tiempo determinado, cuando hablamos de restringir la libertad hablamos de que el condenado no puede seguir desplazándose libremente a donde quiera, por lo general estas condenas se cumplen en un establecimiento carcelario.

Puede haber prisión preventiva llamada medida de aseguramiento, en esta figura se tiene recluido al investigado mientras se define su situación, y por último está el condenado al cual se le restringe su derecho a la libertad y entre otros.

\subsection{PENAS PECUNIARIAS}

Son aquellas condenas que tiene como castigo una sanción que afecta el patrimonio del condenado, esas condenas pueden ser a través de cauciones, multas entre otras, el ejemplo más claro de esta pena la vemos en las sanciones administrativas cuando se infringe una norma de tránsito y como consecuencia se impone un comparendo o en aquellos casos donde las personas están caucionadas y no cumple con esa caución o en las sanciones administrativas cuando entre familiar se imponen medias de protección y aun así no la cumplen. 


\section{ACUERDO ENTRE COLOMBIA Y LA FARC}

Teniendo en cuenta que estamos frente a un acuerdo histórico en nuestro país, no solo por la posibilidad de llegar a un acuerdo con la FARC, si no porque es la primera vez que se observa una posibilidad que en Colombia se pueda vivir sin guerra, esto no quiere decir que el trabajo para recuperar la seguridad en las partes urbana sea corto.

Hay que entender que es un acuerdo de paz y como acuerdo tienen que ceder ambas partes para llegar a un equilibrio, no se puede pretender juzgar a los integrantes de este grupo ilegal con la justicia ordinaria pues de ser así no tendría sentido un acuerdo para ellos, ni habría motivación para que se desmovilizarán, por el contrario se estaría votando a la basura la opción de ver un país en paz, hay que ser realista, aunque el ejército Colombiano se encuentra motivado y capacitado, también es cierto que está agotado de tanta guerra, ni decir de nuestra población civil; podría pasar otros 50 años y no acabaríamos con este grupo guerrillero.

La mayoría de los que han sido afectados por esta guerra (victimas, familias de víctimas) han tomado una decisión que es perdonar, es entendible que haya dolor y rencor por algunas víctimas, pero siempre hemos estado esperando ver un país en paz y ahora que se ve la oportunidad no podemos perderla.

Años atrás no era posible tener la ubicación de los integrantes de este grupo ni mucho mejor de sus jefes, muchos pensaban que eliminando a estas personas se acabaría la guerra pero lo cierto es que la mayoría de los jefes que hicieron parte de la creación de ese grupo ilegal están muertos pero el rencor y el odio sigue y peor aún la guerra, esto demuestra que a pesar de que el tiempo pase no se olvida, y no se olvida porque las nuevas generaciones van creciendo con una realidad y rencor transmitido por sus padres, familia o amigos, pero porque no pensar que se puede trasmitir también a las nuevas generaciones un ambiente de paz, para ello debemos hacer un sacrificio y perdonar para que en un futuro nuestros hijos no tengan la necesidad de pasar por esta decisión y que por el contrario lo único que conozcan de la guerra sea a través de libros de historia para que nunca se vuelva a pensar en que el ser humano se puede autodestruir. 


\section{CONVENCIONES INTERNACIONALES}

Es un acuerdo internacional en el cual un Estado se compromete a cumplir lo pactado (pacta sunt servanda), en nuestro país la Corte Suprema de Justicia en su sentencia c 290 del 2012 ha dicho que las convenciones se acogen a la Constitución política Colombiana, igualmente en la sentencia C 578 del 2002 habla de la constitucionalidad de este estatuto además aclara que aunque hayan delitos que hayan prescripto en Colombia y que sean de competencia de la Corte Penal internacional, podrá investigar y sancionar a los responsable.

Unas de las aclaraciones importantes que hace la Corte en su sentencia C 290 es la anotación de la relación existente entre el Estatuto de Roma y ordenamiento jurídico colombiano al decir lo siguiente:

[...] Seguidamente, esta Corporación se dispuso a realizar unas anotaciones adicionales importantes acerca de las relaciones existentes entre el Estatuto de Roma y el ordenamiento jurídico colombiano, entre las cuales se destacan: (i) las normas del Estatuto surten efectos dentro del ámbito de la competencia de la Corte Penal Internacional; (ii) las disposiciones en él contenidas no remplazan ni modifican las leyes nacionales de tal manera que a quien delinca en el territorio nacional se le aplicará el ordenamiento jurídico interno y las autoridades judiciales competentes al efecto son las que integran la administración de justicia colombiana; (iii) cuando la CPI ejerza su competencia complementaria en un caso colombiano, podrá aplicar en su integridad el texto del Estatuto de Roma; (iv) cuando las autoridades colombianas cooperen con la Corte Penal Internacional y le presten asistencia judicial, en los términos de las Partes IX y X del Estatuto y demás normas concordantes, aplicarán las disposiciones del tratado dentro del ámbito regulado en él; y (v) el tratado no modifica el derecho interno aplicado por las autoridades judiciales colombianas en ejercicio de las competencias nacionales que les son propias dentro del territorio de la República de Colombia?

La Corte identifica una relación entre el Estatuto de Roma y el ordenamiento interno colombiano, en el caso nos cuenta que las normas internacionales tienen competencia en la Corte Penal Internacional, pero estas no modifican las normas internas de un Estado, es decir que una persona que delinque en su país deberá ser juzgado por las normas internas de ese país y no con normas competente de la Corte Penal Internación al igual la Corte Penal Internacional no podrá juzgar 7 sentencia C 290 Corte Constitucional Colombiana 
a una persona con las normas internas del país donde se cometió el hecho ni mucho menos con normas de un tercer país, en otras palabras cada autoridad actúa según sus normas y procedimientos.

\section{CONVENCIÓN AMERICANA SOBRE DERECHOS HUMANOS (PACTO DE SAN JOSÉ)}

El pacto de San José se realizó en Costa Rica el 07 de noviembre de 1969, pero Colombia lo ratifica el 28 de mayo de 1973, motivo por el cual se compromete a cumplir lo allí pactado. En el preámbulo de esta convención los Estados Americanos se comprometen:

Reafirmando su propósito de consolidar en este Continente, dentro del cuadro de las instituciones democráticas, un régimen de libertad personal y de justicia social, fundado en el respeto de los derechos esenciales del hombre;

Es decir que ante todo los Estados deben buscar una armonía generalizada para que todos podamos vivir en paz y sin ningún tipo de restricción de la libertad física ni moral.

Mirando esto, tendríamos que hacernos una pregunta, ¿es más importante meter a la cárcel a unos guerrilleros para que cumplan con penas altas o hacer un acuerdo de paz con ellos donde y así lograr una convivencia en paz?

La discusión se centra en que parte de la población quiere cárcel y muerte para los guerrilleros, ¿pero es posible llegar a un acuerdo donde los responsables de delitos que van en contra de los derechos humanos no paguen penas privativas de la libertad?

El artículo cuarto del pacto de San José nos dice:

Toda persona tiene derecho a que se respete su vida. Este derecho estará protegido por la ley $[\ldots]^{9}$.

Lo que indica que todo Estado debe proteger la vida y en caso de que la vulnere debe castigar al responsable, es decir que debe haber una sanción, la pena no necesariamente es privativa de la libertad, pues hay varios tipos de sanciones como las describí anteriormente, sin embargo, el punto sexto del artículo quinto

8 Convención americana sobre derechos humanos (pacto de san José)

9 Convención americana sobre derechos humanos (pacto de San José) 
nos habla de pena privativa de la libertad y es claro este pacto en decir que la finalidad de esta pena es reformar y readaptar socialmente al condenado.

Esta convención nos dice que no se puede cometer delito en contra de los derechos humanos, pues el Estado debe proteger los derechos del ser humano, pues los tiene por el simple hecho de existir, en caso de que se alteren dichos derechos, el Estado debe investigar y castigar al responsable, pero con el fin de resocializarlo, no por venganza. Este es el fin de la pena, la cual no habla que haya un mínimo de condena privativa de la libertad.

\section{PACTO INTERNACIONAL DE DERECHOS CIVILES Y POLÍTICOS}

Son aquellos derechos humanos, estos derechos están considerados como un derecho de libertad en el cual el Estado debe intervenir lo menos posible en la restricción de libertades, solo lo hará cuando se ponga en riesgo los derechos de terceras personas.

El 16 de diciembre de 1966 la Asamblea General de las Naciones Unidas adoptó el Pacto Internacional de Derechos Civiles y Políticos lo cual se consideró como el fortalecimiento a la Declaración Universal de los Derechos Humanos de 1948.

En este pacto los Estados miembros reconocen que la persona tiene unos derechos que no pueden ser restringidos como la libertad, esto no quiere decir que no pueda imponer reglas pues a la vez debe garantizar la protección integral tanto física como moral de las personas ya que sin esos derechos no es posible que se desarrolle la persona como ser humano y es en el preámbulo donde está el compromiso de buscar la libertad, la justicia y la paz, no solo la parte interna de cada Estado sino a nivel mundial para que estos derechos sean protegidos en cualquier país del mundo sin importar la raza, credo, condición económica, cultural o cualquier otro grupo.

\section{PREÁMBULO}

Los Estados Partes en el presente Pacto,

Considerando que, conforme a los principios enunciados en la Carta de las Naciones Unidas, la libertad, la justicia y la paz en el mundo 
tienen por base el reconocimiento de la dignidad inherente a todos los miembros de la familia humana y de sus derechos iguales e inalienables,

Reconociendo que estos derechos se derivan de la dignidad inherente a la persona humana,

Reconociendo que, con arreglo a la Declaración Universal de Derechos Humanos, no puede realizarse el ideal del ser humano libre en el disfrute de las libertades civiles y políticas y liberado del temor y de la miseria, a menos que se creen condiciones que permitan a cada persona gozar de sus derechos civiles y políticos, tanto como de sus derechos económicos, sociales y culturales,

Considerando que la Carta de las Naciones Unidas impone a los Estados la obligación de promover el respeto universal y efectivo de los derechos y libertades humanos ${ }^{10}$.

En este pacto los Estados se comprometen a buscar la libertad, justicia y la paz en el mundo ya que estos derechos son inherente a la persona y por ser tan importantes son inalienables, motivo por el cual el Estado debe luchar por la búsqueda de la libertad de sus ciudadanos e, incluso por aquellos que no lo son pero que se encuentran en su territorio, por otra parte la justicia es un elemento importante en la dignidad de la persona, pues cuando se le han violado los derechos solo justicia se puede remediar en algo el daño que le han causado y por último, tenemos la paz que es el elemento más importante pues este es la unión de los dos antes dichos pues al haber paz no se violaría ningún derecho ya que la paz es la armonía en la convivencia entre personas que conviven e, incluso entre el Estado.

Los derechos nombrados son importantes para que la persona se realice como ser humano y pueda disfrutar de su libertad y todos sus derechos tanto civiles, políticos, económicos, culturales y sociales por eso es obligación del Estado proteger estos derechos. En Colombia por el conflicto interno que se vive desde hace más de 50 años se han violados diferentes derechos que afectan los derechos fundamentales de las personas y es por esto que el Estado debe buscar un acuerdo en donde se erradique la violación de estos derechos, pero siempre cumpliendo con una justicia para aquellos a los que se le han violado sus derechos y cuando hablamos de justicia nos referimos no solo a una condena, también a una reparación de los daños que le causaron.

10 Pacto de derechos civiles y político 
En este pacto se determina que los Estados tienen una autonomía para implementar sus políticas que le permitan garantizar la protección de los derechos dentro de sus territorios, esto lo encontramos en el artículo 1 de la parte I del pacto Internacional de derechos políticos y civiles así:

1. Todos los pueblos tienen el derecho de libre determinación. En virtud de este derecho se establece libremente su condición política y proveen asimismo a su desarrollo económico, social y cultural.

2. Para el logro de sus fines, todos los pueblos pueden disponer libremente de sus riquezas y recursos naturales, sin perjuicio de las obligaciones que derivan de la cooperación económica internacional basada en el principio del beneficio recíproco, así como del derecho internacional. En ningún caso podrá privarse a un pueblo de sus propios medios de subsistencia ${ }^{11}$.

Este artículo nos dice que los Estados tienen una libertad para implementar sus medios de protección de derechos dependiendo del tipo de sociedad o cultural en que se encuentren, lo importante es que las normas o políticas que se implementen no violen ninguno de los derechos protegidos en este pacto o en aquellos que protegen derechos a nivel internacional como los derechos humanos.

Igualmente, en el artículo 3 del pacto de los derechos políticos y civiles encontramos el compromiso de cada Estado en la protección de los derechos del hombre.

Los Estados Partes en el presente Pacto se comprometen a garantizar a hombres y mujeres la igualdad en el goce de todos los derechos civiles y políticos enunciados en el presente Pacto ${ }^{12}$.

\section{FUNCIÓN DE LA PENA}

Como hemos hablado de una condena para aquellas personas que han cometidos delitos crueles que van en contra de la dignidad de las personas, la mayoría quiere muerte o cadenas perpetúa, pero tenemos que tener en cuenta que para ello también hay normas internacionales como la que encontramos en el numeral 3 del artículo 10 que dice:

11 Pacto de derechos civiles y políticos

12 Pacto de derechos civiles y políticos 
3. El régimen penitenciario consistirá en un tratamiento cuya finalidad esencial será la reforma y la readaptación social de los penados ${ }^{13}$.

No cabe duda de que hay un sentimiento de rencor así los que cometen delitos crueles y tal vez la única forma de devolverle en algo la tranquilidad es darle un poco de justicia, cuando digo algo es porque en un conflicto muchas veces hay que hacer sacrificios para encontrar la paz. Cuando hablamos de víctimas nos referimos también a los familiares de estos ya que en algunos casos son los que más sufren al no saber dónde se encuentran sus familiares o incluso saber si aún viven.

\title{
11. CONVENCIÓN CONTRA LA TORTURA Y OTROS TRATOS O PENAS CRUELES, INHUMANOS O DEGRADANTES
}

Colombia firma esta convención el 10 de abril de 1985 y la ratifica el 08 de diciembre de 1987, en este acuerdo los países proclaman como principio que el reconocimiento de los derechos iguales e inalienables de todos los miembros de la familia humana es la base de la libertad, la justicia y la paz en el mundo, motivo por el cual los Estados deben encontrar la paz del mundo.

Los actos inhumanos deben ser castigados conforme lo vimos en la declaración de los derechos humanos; la convención contra la tortura en su artículo primero define uno de estos tratos así:

\begin{abstract}
[...] tortura" todo acto por el cual se inflija intencionadamente a una persona dolores o sufrimientos graves, ya sean físicos o mentales, con el fin de obtener de ella o de un tercero información o una confesión, de castigarlas por un acto que haya cometido, o se sospeche que ha cometido, o de intimidar o coaccionar a esa persona o a otra, o por cualquier razón basada en cualquier tipo de discriminación, cuando dicho dolores o sufrimientos sean infligidos por funcionarios públicos u otras persona en el ejercicio de funciones públicas, a instigación suya, o con su consentimiento o aquiescencia $[\ldots]^{14}$.
\end{abstract}

El estado debe tomar medidas tanto legislativas, administrativas, judiciales o las necesarias en derecho para evitar dichos tratos.

\footnotetext{
13 Pacto de derechos civiles y políticos

14 Convención contra la tortura y otros tratos o penas crueles, inhumanos o degradantes
} 
Una de las obligaciones que tienen los países al acoger a esta convención es que tiene que vincular todo acto de tortura como delito (artículo 4.1 convención contra la tortura), esto Colombia lo ha cumplido cuando observarnos en el código penal colombiano (ley 599 del 2000) en sus artículos 137 tortura en persona protegida, 170.2 circunstancias de agravación punitiva (someter a la víctima a tortura), 178 tortura, 340 (modificado por el artículo 19 ley 1121 del 2006) concierto para delinquir (cuando el concierto sea para cometer delitos de genocidio, desaparición forzada de personas, tortura..), 415 circunstancia de agravación punitiva, 441 omisión de denuncia de particular, 446 favorecimiento entre otros. Por lo que podemos observar dentro de la ley interna colombiana se castiga todo tipo de actos de tortura, crueles e inhumanos, lo que muestra que se ha acogido al requerimiento de la convención.

Igualmente, el artículo 12 (convención contra la tortura y otros tratos o penas crueles, inhumanas o degradantes) dice:

[...] todo Estado parte velara por qué siempre que haya motivo razonable para creer que dentro de su jurisdicción se ha cometido un acto de tortura, las autoridades competentes procederán a una investigación pronta e imparcial ${ }^{15}$.

En el acuerdo que platea el gobierno colombiano con la Farc, en ningún momento se está negando a investigar lo sucedido; por otra parte, el número segundo del artículo 4 de la misma convención obliga a los Estados que deben imponer penas adecuadas a la gravedad de la conducta, pero no dice que haya una regla de condenas para cada delito, es potestad de cada Estado imponer esas penas de acuerdo con su criterio sin salirse de lo acordado en la convención.

De las exigencias internacionales para condenas delitos cometidos en contra de los derechos humanos podemos ver que Colombia y la Farc manifestaron que si van a ver condenas como lo establece la convención en comento.

12. LA PAZ

La paz es un derecho que le corresponde a las personas y al estado en otras palabras a la humanidad en general, por eso debe haber un esfuerzo que permita encontrar este derecho.

15 Convención contra la tortura y otros tratos o penas crueles, inhumanos o degradantes 
La paz va ligada con el desarrollo económico, si no hay paz no pude haber crecimiento económico, pues la guerra, la destrucción de infraestructuras, la muerte, el secuestro, la extorsión, son obstáculos que no permite el desarrollo de un país. Sin embargo, la paz no constituye solo un desarme militar este debe ir acompañado de un desarrollo cultural, económico y social.

La paz y el desarrollo juntos constituyen uno de los elementos fundamentales de la humanidad, cuando hablamos de desarrollo no nos referimos solo a un crecimiento económico sino a aquel que va acompañado de un desarrollo social, cultural y político de la persona, del estado y de la humanidad, como podemos ver estos términos van muy ligados a la paz.

Este derecho es fundamental para la humanidad por tanto la fuerza para la búsqueda de la paz debe ser más fuerza que la de guerra.

\section{ACUERDO DE PAZ EN EL SALVADOR}

Unos de los ejemplo cercanos de estados que han conseguido llegar a un acuerdo de paz con guerrillas es el caso del salvador que tras doce años de conflicto decidieron llegar a un acuerdo de paz el 16 de enero del 1992 con el Frente Farabundo Martí para la Liberación Nacional, en este camino hubo inconvenientes pero tras la intervención de la Naciones Unidas lograron llegar a un acuerdo que abarcaba cinco áreas fundamentales como la modificación de las fuerzas armadas, creación de la Policía Nacional Civil, modificaciones al sistema judicial y a la defensa de los Derechos Humanos, modificación en el sistema electoral y adopción de medidas en el campo económico y social.

Esto nos indica que el camino a la paz no es fácil pero como lo hemos nombrado en varias oportunidades en este trabajo es obligación del estado poner todos sus esfuerzos para lograr encontrar esa paz.

\section{ACUERDO DE PAZ EN GUATEMALA}

Guatemala es otro de los países latinos que tenemos como referencia en un acuerdo de paz, pues este país vivió un conflicto interno armado con la denominada guerrilla Unidad Revolucionaria Nacional Guatemalteca -URNG, por un periodo que duro tres décadas, en este periodo se causaron actos de crueldad, desprecio a la vida y a la dignidad de la población. 
Después de aproximadamente 36 años, el 29 de diciembre de 1996 se firma la paz entre el gobierno de Guatemala y la llamada guerrilla de Revolución Nacional Guatemalteca, en este acuerdo se tuvieron 17 puntos, entre ellos el compromiso de investigar las violaciones de los derechos humanos causados en el conflicto interno para contribuir a fortalecer el proceso de conciliación nacional y la democratización del estado, el reconocimiento de los derechos de pueblos indígenas y a mantener su identidad con el fin de la construcción de una nación multiétnica, pluricultural y multilingüe, en donde se erradique la pobreza, el desempleo, se mejore la atención a la salud, la educación, la capacitación y la seguridad social con el objetivo de encontrar un estado justo y armónico donde la se cumpla.

Como podemos ver en los dos casos hubo conflictos internos armados con grupos ilegales llamados guerrillas en la cuales hubo claras violaciones a los derechos humanos incluso según estudios internos en el caso de Guatemala muchos de esos casos fueron cometidos por miembros del ejército, motivo por el cual la guerrilla no estaba dispuesta a negociar ya que consideraba que no había justicia.

También podemos ver que en la búsqueda de la paz en estos países hubo muchos fracasos pero luego de la intervención de terceros como la ONU fue posible que llegara a un acuerdo, algo que no es diferente a lo que pasa en Colombia, pues se han hecho varios intentos en la búsqueda de la paz pero estos han fracasado, solo ahora que han intervenidos diferente y todos apuntando a un mismo objetivo vemos más cerca esa ilusión de encontrar la paz en un país que no quiere más guerra, solo vivir en armonía.

\section{CONSIDERACIONES FINALES}

Los acuerdos de paz esta permitidos por las convenciones internacionales, pero estos deben estar sometidos siempre a la protección de los seres humanos, por lo tanto, el Estado debe hacer todo lo posible para que los derechos que son inalienables de la persona se cumplan, para ello debe implementar normas internas de protección y de sanción para aquellos que la infrinja.

La Corte Penal Internacional ha determinado su competencia para aquellos delitos llamados delitos internacionales y los ha clasificado en cuatro categorías 
de las cuales actualmente tiene competencia sobre tres de ellos, que son los llamados delitos de genocidio, crímenes de lesa humanidad y crímenes de guerra.

Las categorías de estos delitos son tan importantes que se aplican a nivel mundial y no pueden ser violados por ningún motivo ni por ningún Estado ya que son aquellos derechos que se encuentran adheridos a la persona y sin ellos no es posible llegar a desarrollarse o realizarse como ser humano, motivo por el cual el Estado tiene la obligación de protegerlos y sancionar a quienes los lesione.

Los acuerdo internacionales han determinado que los Estados tienen autonomía para implementar normas internas con el fin de proteger derechos y sancionar a aquellos que la infrinjan, pero estos deben estar sometidos a las convenciones sobre derechos humanos pues de no hacerlo podrían verse involucrados en futuras condenas internacionales como Uruguay en el caso Gelman vs Uruguay donde fue condenado por que no hubo una protección de los derechos humanos y más aún cuando el Estado se negó a investigar y sancionar a los responsables. En el caso de estudio, el gobierno colombiano da a conocer una serie de puntos en donde plantea una serie de condenas para aquellas personas que reconozcan sus delitos cometidos dentro $y$, como consecuencia del conflicto armado interno cumpliendo unos requisitos, como reconocer los hechos, contar la verdad y aceptar su responsabilidad en los hechos cometidos, adicionalmente deberán reparar a las víctimas y también debe haber un compromiso de resocialización a través del trabajo, estudio dentro del período de la condena para poder ser beneficiario de una justicia especial y tal vez el punto más importante en este comunicado es el compromiso de no repetición, pues así se garantiza que la paz va ser segura y duradera.

En un acuerdo de paz tenemos que tener en cuenta el Estatuto de Roma, la convención americana sobre derechos humanos, la convención contra la tortura y otros tratos o penas crueles inhumanos o degradantes y el pacto internacional de derechos civiles y políticos, aunque hay más convenciones, de estas se desprenden las demás y si se cumple con lo aquí pactado la Corte Penal Internacional no tendría competencia para juzgar, pues solo tiene competencia cuando la norma interna de un Estado no puede garantizar sus derechos, la Corte Constitucional de Colombia ha dicho que las convenciones no modifican las normas o competencias internas de un Estado. 
Considero yo que, si el Estado cumple con las normas que impone las convenciones Internacionales sobre derechos humanos, no tendría competencia para sancionarlo, pues el mismo pacto de derechos civiles y políticos dice que los Estados tiene autonomía para proteger sus derechos. Las convenciones que hemos tratado en el trabajo habla que los Estados tienen la obligación de investigar y sancionar a aquellos que violen estos derechos $y$, es precisamente esto lo que ha manifestado el gobierno colombiano al decir que se va a investigar, los involucrados en este conflicto para ser beneficiarios de este acuerdo deberán contar la verdad con el fin de buscar una justicia en la que las víctimas se reparen por los daños sufridos y como sanción a los responsables habrán condenas con restricción de la libertad.

Ya para concluir las mismas convenciones obligan a los Estados a garantizar la armonía y convivencia en un ambiente de paz en el mundo, lo que hace que un acuerdo de paz sea casi una obligación para los Estados con el fin de evitar que se continúen cometiendo delitos inhumanos en contra de la humanidad. La paz no es un camino fácil y requiere de sacrificios, el primero de ellos es apartar el rencor, el odio con el fin de encontrar el perdón, la armonía y la paz interior como exterior de la persona para que se refregué ante la sociedad. El acuerdo se acoge a los acuerdos internacionales, las altas penas de prisión no es una obligación pues hay diferentes tipos de condenas y la función de esta es la resocialización del condenado con el objetivo de reintegrarse a la sociedad para no volver a delinquir.

Esta tesis no supone verdad. Es tan solo mi punto visto. Sea bienvenido el debate.

\section{REFERENCIAS DE LAS FUENTES CITADAS}

Artículo de la Naciones Unidas - acuerdo de paz del Salvador http://www.onu.org.gt/ contenido.php?ctg=1393-1341-acuerdos-de-paz tomada el 10/11/2015

Artículo de las Naciones Unidas - acuerdo de paz en Guatemala http://www.onu.org.gt/ contenido.php?ctg=1393-1341-acuerdos-de-paz tomado el 10/11/2015

Artículosobregenocidiohttp://www.ushmm.org/wlc/es/arGGGticle.php?ModuleId=10007251 tomado el 06/07/2015

Artículo- marquetalia- Creación de la Farc http://historico.unperiodico.unal.edu.co/ ediciones/57/03.htm tomado el 09/11/2015

Código penal colombiano (ley 599 del 2000) Editorial Legis 2014

Convención Americana sobre derechos humanos - Pacto de San José, Costa Rica de 1969 
http://www.oas.org/dil/esp/tratados B-32 Convencion Americana sobre Derechos_umanos. htm tomada el 12/ 10/2015

Convención contra la tortura y otros tratos o penas crueles, inhumanas o degradantes http:// www.pgjdf.gob.mx/temas/4-6-1/fuentes/11-A-2.pdf tomada el 05/11/2015

Convenios de Ginebra del 1 de agosto de 1949 https://www.icrc.org/spa/assets/files/ publications/convenios-gva-esp-2012.pdf tomados el 12/10/2015

Constitución Española de 1978 http://www.boe.es/buscar/act.php?id=BOE-A-1978-31229 tomada el 09/11/2015

Constitución política Colombiana Editorial Legis

Derecho a la paz y el derecho internacional del desarrollo http://biblio.juridicas.unam.mx/ libros/1/258/3.pdf tomado el 10/11/2015

Documento del autor ENRIQUE NEIRA FERNANDEZ, tema delitos internacionales http://www. saber.ula.ve/bitstream/123456789/14037/1/delitos.pdf tomado el 07/10/2015

Documento sobre delitos de agresión http://www.iccnow.org/?mod=aggression\&lang=es tomado el 06/11/2015

Enciclopedia jurídica - pena infamante http://www.enciclopedia-juridica.biz14.com/d/penainfamante/pena-infamante.htm tomada el 07/11/2015

Enciclopedia Jurídica - Penas pecuniarias http://www.enciclopedia-juridica.biz14.com/d/ penas-privativas-de-derechos/penas-privativas-de-derechos.htm tomada el 07/11/215

Estatuto de Roma de la Corte Penal Internacional http://www.un.org/spanish/law/icc/statute/ spanish/rome statute(s).pdf tomado el 07/11/2015

Historia de la Fuerza Armada de Revolución Colombiana- Farc http://www.perfil.com/ internacional/La-historia-de-las-FARC-desde-sus-inicios-20080702-0039.html tomada el 09/11/2915

Pactointernacionaldederechoscivilesypolíticos http://www.ohchr.org/SP/ProfessionalInterest/ Pages/CCPR.aspx tomado el 08/11/2015

Disertación - Paz, desarme y desarrollo Autor: Mario Moya Palencia http://biblio.juridicas. unam.mx/libros/1/258/9.pdf tomada 10/11/2015

Sentencia C-290/12 de la Corte Constitucional Colombiana http://www.corteconstitucional. gov.co/RELATORIA/2012/C-290-12.htm tomada el 20/10/2015

Sentencia de la Corte Penal Internacional del 24 de febrero del 2011 - caso Gelman vs Uruguay http://www.corteidh.or.cr/docs/casos/articulos/seriec 221 esp1.pdf tomada el 07/11/2015

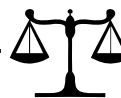

Recebido em: maio/2018

Aprovado em: julho/2018 